\title{
O PERFIL DOS ALUNOS DE ADMINISTRAÇÃO MATRICULADOS NAS DISCIPLINAS DA ÁREA CONTÁBIL: O CASO DO CENTRO DE EDUCAÇÃO A DISTÂNCIA DO ESTADO DO RIO DE JANEIRO (CEDERJ)
}

\section{(THE PROFILE OF BUSINESS ADMINISTRATION STUDENTS ENROLLED IN ACCOUNTING: THE CASE STUDY OF THE DISTANCE EDUCATION CENTER OF RIO DE JANEIRO STATE)}

Robson Augusto Dainez Condé

Renato Santiago Quintal

Silvestre De Mello De Souza

Simone Silva Da Cunha Vieira

Universidade do Estado do Rio de Janeiro, UERJ (Brasil)

\section{RESUMO}

O presente artigo tem o objetivo de identificar o perfil dos discentes do curso de administração do Centro de Educação a Distância do Estado do Rio de Janeiro (CEDERJ) matriculados nas disciplinas da área contábil. Trata-se de uma pesquisa empírica, de abordagem qualitativa e quantitativa; e exploratória, no que se refere aos procedimentos utilizados. O instrumento de coleta de dados foi o banco de dados disponibilizado pelo CEDERJ. A estratégia de data mining possibilitou a extração dos dados e o subsequente tratamento estatístico. Ao final da pesquisa, vislumbrou-se a construção do perfil do alunado de Administração matriculado nas disciplinas afetas à contabilidade, especialmente no que tange a: sexo; distribuição geográfica; faixa etária; desempenho e evasão apresentados ao longo do curso.

Palavras chave: educação a distância, administração, contabilidade, perfis, CEDERJ.

\begin{abstract}
This article aims to identify student profiles in the distance-based Business Administration degree offered at the Distance Education Centre (CEDERJ), based in the State of Rio de Janeiro. It concerns an empirical study of students who are enrolled in the fields of Accounting. The study, which is of a qualitative, quantitative and exploratory nature,
\end{abstract}


focuses on tried and tested methods. The instrument used for data collection was the database provided by CEDERJ. Moreover, the data-mining strategy facilitated the extraction of the data and the subsequent statistical processing methods. At the end of the study, it was possible to construct the student profile of students taking Business Administration, namely those who were enrolled in academic disciplines related to Accounting. The study looked at the following issues: gender, geographical distribution, age groups, performance as well as attrition that occurred during the course.

Keywords: distance education, administration, accounting, profiles, CEDERJ.

O avanço das tecnologias da informação e comunicação modificou o dia a dia das pessoas e das organizações. Os conceitos de distância e de tempo foram reduzidos virtualmente e, atualmente, é possível realizar uma reunião por vídeo conferência com pessoas situadas em diversos países ao mesmo tempo. Segundo Mota (2007) o desenvolvimento destas tecnologias tem provocado uma profunda revolução na divulgação do conhecimento e, nesse contexto, a educação a distância tem sido potencializada pela facilidade de compartilhamento do conhecimento e pela possibilidade de escolha sobre o método de aprendizado.

A academia por vários anos travou discussões acerca da viabilidade da Educação a Distância e, nos dias atuais, a criação, uso e disseminação dessa modalidade de ensino, já é realidade para algumas instituições. Essa tendência tem início e se fortalece conforme os anseios de diversos segmentos da sociedade, nacional ou internacional. Exterioriza-se por meio de novos modos de interagir, competir ou compor a sociedade. A Educação a Distância segue essa nova "conjuntura de tecnologia, comunicação, trabalho em grupo, flexibilidade e conhecimento", que caracteriza a sociedade da informação globalizada (Prata, 2003).

O presente artigo tem o objetivo de apresentar o desempenho dos discentes do curso de administração inscrito nas disciplinas afetas à contabilidade, face à relevância dos conhecimentos contábeis para a formação do futuro administrador.

\section{REVISÃO DE LITERATURA}

\section{O crescimento da educação à distância no Brasil}

Para Santos (2006) o fenômeno da Internet possibilitou que o ensino e aprendizagem não ficassem limitados somente à sala de aula no aspecto da interação tradicional entre aluno e professor, mas além das delimitações físicas, permitindo a 
construção do conhecimento pelo discente no seu universo doméstico, profissional ou outro por ele desejado.

Para Prata (2003), no contexto brasileiro, à Educação a Distância é reservada a função estratégica no método de "universalização e democratização do ensino", especialmente devido às "desigualdades regionais de déficits educativos". A "alfabetização digital" procura resgatar a "cidadania negada" a um sem número de cidadãos brasileiros em face da falta de acesso às benesses proporcionadas pela tecnologia.

Por outro lado, Bahia e Duran (2011) realizaram pesquisa com objetivo de traçar o perfil dos alunos do curso de pedagogia na modalidade à distância. De um modo geral esses alunos expressaram a satisfação com o curso na modalidade à distância, mas evidenciaram sentimentos negativos sobre o curso, percebidos na relação com familiares e amigos, que parecem atribuir menor prestígio ou descrédito ao curso. Ainda assim, a demanda por esta modalidade de curso vem crescendo nos últimos anos.

A tabela 1 compara as taxas de crescimento acumulada de alunos matriculados nas modalidades presenciais e a distância, entre 2002 e 2007, revelando a importância da modalidade à distância no cenário atual:

\begin{tabular}{|l|c|}
\hline \multicolumn{2}{|c|}{ Taxa de Crescimento Acumulada entre 2002 e 2007} \\
\hline Graduação presencial & $38 \%$ \\
\hline Graduação a distância & $808 \%$ \\
\hline
\end{tabular}

Tabela 1. Comparação entre taxas de crescimento acumulada de matrículas: período 2002 a 2007 Fonte: Secca e Leal (2009), a partir de dados coletados do Censo da Educação Superior 2007 (INEP)

Secca e Leal (2009) inferem que a Educação a Distância pode representar a diminuição de custos e o incremento da capilaridade das Instituições de Ensino Superior, por possibilitar o atingimento de um maior quantitativo de alunos por docente por meio da utilização de dispositivos tecnológicos. Adicionalmente, reduz a necessidade de utilização de salas de aula e alcança estudantes em que não existe Instituições de Ensino Superior fisicamente instaladas. Para os autores em lide, "as Instituições de Ensino Superior que não oferecerem EAD estarão fora de um mercado que é novo e cresce rapidamente”. 
Schlickmann et al. (2009) estudaram os fatores determinantes na opção do aluno pela modalidade à distância a fim de verificar se os resultados coincidem com as observações de outros pesquisadores. Os resultados demonstraram que a flexibilidade é a característica determinante na opção dos alunos pelo ensino à distância, por possibilitar a compatibilidade da educação com as realidades dos discentes. A pesquisa avaliou ainda o perfil sócio-econômico dos discentes e apontou que em sua maioria os alunos são adultos, trabalham e têm larga experiência de vida.

Em um contexto de real crescimento da demanda pelo ensino à distância, os governos têm empreendido estratégias para potencializar sua competitividade baseada na disseminação e diversificação do conhecimento por meio desta metodologia de ensino. No Brasil, o MEC (Ministério da Educação) administra diversos programas sobre a educação à distância, entre os quais: i) o programa UAB (Universidade Aberta do Brasil) que busca ampliar e interiorizar a oferta de cursos superiores na modalidade à distância, com objetivo de reduzir as desigualdades na oferta do ensino superior; ii) o Sistema Rede e-Tec Brasil, programa lançado em 2007, que oferece educação profissional e tecnológica à distância, com o propósito de democratizar o acesso a cursos técnicos de nível médio, públicos e gratuitos; e iii) o Mídias na Educação, programa de educação à distância, com estrutura modular, que visa fornecer formação continuada para o uso pedagógico das diferentes tecnologias da informação e comunicação, destinado prioritariamente a professores da educação básica (Brasil, 2012).

\section{Pesquisas sobre desempenho e avaliação de alunos na Educação a Distância}

Abdala et al. (2007) realizaram pesquisa sobre o desempenho de alunos do curso de Administração da PUCRS, na disciplina Teoria Geral da Administração disponibilizada, na modalidade à distância. Os principais achados da pesquisa foram a baixa evasão dos estudantes nesta modalidade de ensino, a constatação que o índice de reprovação é semelhante ao das demais disciplinas no semestre e a percepção dos discentes de que a modalidade a distância contribui para aprendizagem e qualificação profissional dos alunos.

Pacheco et al. (2008) realizaram um estudo sobre evasão no curso de graduação em Administração à distância da Universidade Federal de Santa Catarina. Os resultados apontaram mais de um fator como responsável pela evasão dos alunos no curso. Entre estes fatores pode-se citar, por exemplo, o distanciamento ou a falta de contato dos discentes com os professores e os tutores. 
Mora e Gómez (2011) pesquisaram os determinantes do rendimento acadêmico de novos estudantes em uma instituição de ensino superior à distancia do Equador. Para isso, descreveu o perfil destes estudantes, considerando variáveis qualitativas, como sexo e região de localização do centro universitário e variáveis quantitativas, como idade. Os resultados indicaram que estes fatores podem influenciar o desempenho acadêmico do discente, determinando o seu sucesso ou fracasso.

O processo de avaliação do estudante sempre representou um desafio aos professores em face da dificuldade de percepção acerca do aprendizado do estudante. A avaliação detém consequências pedagógicas que extravasam as considerações técnicas e metodológicas e abarcam "aspectos sociais, éticos e psicológicos" (Campos, 2002, apud Prata, 2003). Conforme Chadernet (2002, apud Prata, 2003), não existe uma teoria geral de avaliação do aluno, mas uma suposição denominada "noção" do processo dinamico de aprendizagem do estudante.

Até o início da década de 80, o objetivo da avaliação era medir os resultados do ensino, funcionando como garantidora da qualidade da aprendizagem. A partir daquele período, essa maneira de avaliar revestiu-se de nova roupagem com a finalidade de aperfeiçoar o ensino. Uma das características da avaliação é a sua aplicação no aprimoramento da "qualidade e produtividade da aprendizagem". Essa nova abordagem produziu refelexões acerca da sua complexidade, provocando modificações, sendo examinada como processo, de natureza intrínseca, agregada à aprendizagem. A avaliação não é mais considerada como um fim, sobretudo como meio, agindo mutuamente com ténicas e metodologias de aprendizagem (Prata, 2003).

Para Ângelo (1999, apud Prata, 2003) existe a necessidade de que professores alunos estabeleçam a diferença entre avaliação e nota. A modificação cultural refletida na proposta de alteração do modelo de avaliação classificatória, vigente ao longo de várias décadas, trata-se de um processo complexo que demandará tempo. Para alguns profissionais, a avaliação consiste em um "processo técnicomecanicista", uma coletânea de ferramentas de monitoramento, materializadas em perguntas a serem esclarecidas que podem fazer parte dos programas acadêmicos. Já outros professores vislumbram a avaliação como um "aborrecimento periódico, necessário", percepção atribuída provavelmente ao condicionamento recebibo pelas "experiências de credenciamento oficiais".

A avaliação é responsável por provocar ansiedade em educadores e alunos. Em relação aos professores, pairam questionamentos acerca da "qualidade, lealdade, 
justiça, integridade, imparcialidade, confiabilidade, privacidade, eficiência e honestidade da avaliação". No que se refere aos alunos, "há medo, a insegurança, a humilhação, a desconfiança, a ira, a indignação, a divergência”. Existe a dúvida em relação aos sentimentos associados à avaliação no ensino a distância; teria o mesmo carater provocador da avaliação conduzida no ensino presencial? (Prata, 2003).

Para Prata (2003) existe a possibilidade da divisão dos desafios relacionados à avaliação à distância em cinco categorias: a pedagógica, a didática, a ética, a psicológica, e a tecnológica. A abordagem pedagógica está relacionada à "estruturação e organização do conhecimento". A didática refere-se à maneira como esse conhecimento é transmitido ao educando (Chardenet, 2002, apud Prata, 2003). A abordagem ética está relacionada aos "problemas éticos" atrelados "à didática e à tecnologia de ensino"; individualmente em relação ao educador e ao aluno e socialmente em relação à instituição de ensino. A abordagem psicológica relacionase à delimitação do "perfil e acompanhamento emocional do aluno". Por último, a abordagem tecnológica abarca a "logística necessária para atender os requisitos do ambiente de avaliação" (Prata, 2003).

Para Prata (2003) a categoria pedagógica refere-se à distinção entre avaliação e classificação do discente; ao preparo do docente para avaliação em ensino a distância; à instituição da visão do docente como indutor do processo de aprendizagem; e à promoção da avaliação dos discentes sob a ótica da aprendizagem colaborativa. Para o autor em lide, a didática proporciona ao professor instrumentos voltados à "avaliação continuada, tradicional, alternativa", sob o prisma social. A ética viabiliza a criação de um cenário que acomapnha os parâmetros éticos de avaliação em âmbito individual e social. A categoria psicológica é responsável pela motivação do aluno para que ele não abandone o curso, permitindo que o professor, ao conhecer o perfil emocional do discente, perceba o seu ânimo diante do curso. A tecnologia facilita o processo de avaliação, estabelecendo sistemáticas de avaliação amigáveis a docentes e discentes, além de atuar, recentemente, instrumento de identificação de plágios em trabalhos acadêmicos (Prata, 2003).

A avaliação compõe uma rotina de ensino "frequente e necessária", revestindose reconhecida de importância. Usualmente, a avaliação tem adotado um viés estritamente "verificacionista e classificatório", em face da utilização de instrumentos de aferição de desempenho, alicerçados na comparação dos alunos entre si e na larga utilização de "parâmetros pré-estabelecidos". Em certas situações, variam de meros exames do comportamento discente frente às tarefas pedagógicas a exames refinados 
gerados à luz de parâmetros técnicos firmados no seio de cada estabelecimento de ensino (David et al., 2007).

Essa visão clássica de avaliação influenciou a Educação a Distância, por meio da utilização assídua de ferramentas de verificação de desempenho, sob aspectos quantitativos. Em determinados Ambientes Virtuais de Apresendizagem (AVA), o processo de avaliação restringe-se a quantificar participações e acessos e a realizar avaliações objetivas, em especial exames de múltipla escolha (Caldeira, 2004).

O amparo da avaliação nesses instrumentos quantitativos implica na restrição do seu potencial. A educação atual, a distância ou presencial, requer a utilização de procedimentos pedagógicos que destaquem a interação entre os envolvidos. Cenários mais recentes em avaliação associam características quantitativas e qualitativas, à semelhança da argumentação e do raciocínio desenvolvido pelos discentes em "situações-problema". Portanto, o propósito da avaliação não deve ser unicamente comprovar o quantitativo de conhecimento obtido pelo aluno acerca de determinada matéria, uma vez que se trata de um indicador difícil de ser estabelecido, mas delimitar estratagemas para auxiliá-lo a edificar os seu saber, a partir dos dados adquiridos em seu acompanhamento (Luckesi, 1998).

A avaliação deve balisar as ações do docente no sentido de que ele seja capaz de proceder as alterações julgadas necessárias a sua atuação, de modo a converter as dificuldades em situações propícias à aprendizagem do alunado. Sob esssa ótica, a avaliação deve se tranformar em uma ferramenta preferencial de um ajustamento permanente das distintas mediações e circunstâncias didáticas (Perrenoud, 1999, p. 14).

A avaliação fornece contribuição acerca da avaliação da eficácia didática e pedagógica dos recursos utilizados, favorecendo ao tomador de decisão ao longo do processo de ensino-aprendizagem, com o objetivo de aperfeiçoar qualitativamente o conhecimento que está sendo edificado. A aferição do desempenho escolar, geralmente, resulta em três rotinas sucessivas realizadas pelos docentes, relacionadas ao aproveitamento escolar e à correspondente mensuração em grau ou conceito, bem como a aplicação dos resultados vislumbrados (Luckesi, 1998).

Libâneo (1991) assevera que não é aconselhável que utilização da avaliação na atividade docente se resuma a uma singela aplicação de testes e a correspondente outorga de notas. Para ele, a mensuração unicamente provê dados qualitativos que necessitam ser considerados qualitativamente. Piletti (1987) e Haydt (2002) 
corroboram com esse entendimento e asseveram que a avaliação trata-se de uma ação de caráter pedagógico indispensável à garantia da qualidade do método ensino-aprendizagem. Para tal, deve atender a três utilidades didático-pedagógicas: utilidade diagnóstica, utilidade formativa, e utilidade somativa.

A utilidade diagnóstica da avaliação envolve reconhecer o conhecimento anterior dos discentes em certa área, notando a ocorrência de exigências básicas necessárias aos novos aprendizados. Sua realização se dá na etapa inicial do curso e objetiva mensurar as prováveis dificuldades na aprendizagem e seus motivos (Haydt, 2002).

A utilidade formativa é utilizada ao longo do processo ensino-aprendizagem permitindo um retorno instantâneo sobre o rendimento do discente, dos pontos fracos da didática utilizada, colaborando para a execução de acertos úteis à articulação do ensino, em face do atingimento dos objetivos delimitados anteriormente (Almeida, 2001).

Por outro lado, a utilidade somativa tem o objetivo de agrupar os discentes conforme os seus estágios de proveito no processo ensino-aprendizagem. A sua realização se dá no encerramento de um curso ou semestre letivo, de acordo com critérios anteriormente estipulados, visando promover o discente de um estágio para outro (Haydt, 2002).

Para David et al. (2007) a modalidade de avaliação que mais contribuiria para as tarefas docentes no que se refere à mediação pedagógica seria a que abarcasse as três utilidades apresentadas anteriormente, ao invés de uma única utilidade. Para Santos (2005, p. 2, apud David et al., 2007), esse modo de avaliação é raramente utilizado no atual cenário educacional, possuindo a avaliação um aspecto "meramente classificatório e descontextualizado".

Lopes e Schiel (2004) afirmam que, na modalidade de ensino presencial, o professor dispõe de variado instrumental de acompanhamento que viabiliza a produção de resultados de grande valia à tomada de decisão. Segundo Linderman (1986), um juízo de valor sobre as possibilidades de sucesso ou fiasco de um estudante nas atividades por ele futuramente empreendidas é formado a partir da análise do seu desempenho atual e passado. Há também a hipótese do docente ordenar os estudante à luz de determinados objetivos escolares. O processo denominado Datadrive Decision Making, também conhecido como D3M, vem sendo utilizado na condução da aprendizagem e correlaciona diversos fatores para aferir o aprendizado 
de modo mais refinado. Esse processo considera a utilização de uma base de dados orientada ao aluno, na qual são agregadas informações sobre a trajetória escolar do discente. Distintas variáveis compõem essa base de dados, em especial: dados demográficos (sexo, idade, escolaridade, procedência, situação financeira); dados comportamentais (frequência de reprovação e desempenho no curso); e dados avaliativos (avaliações do discente). De posse de informações individuais, o docente poderá compreender o resultado pelo enfoque de diversos grupos estudantis, valendo-se da separação e análise das informações através do cruzamento de dados (Lopes e Schiel, 2004).

Lopes e Schiel (2004) afirmam que não há uma prática pedagógica que possibilite o acompanhamento do aprendizado direcionado de modo específico à Educação a Distância. Os autores em lide creditam a Vieira, apud Neder (2002), e a Souza (1999), o fato de que o acompanhamento do processo de aprendizagem em Educação a Distância pode se amparar em princípios que guardam semelhança ao da educação presencial, todavia aconselham que ao mesmo seja acrescentado acompanhamento especial. Lopes e Schiel (2004) categoricamente estabelecem dois tipos de acompanhamento: informal e alternativo.

No acompanhamento informal, são apreendidas algumas particularidades do aprendiz com o objetivo de analisá-las analogamente a maneira de se comportar de um aluno de curso presencial, no qual "a linguagem corporal, o grau de interesse, a participação e a sociabilidade" podem ser observadas sob o prisma da influência recíproca aluno-ambiente, providenciando meios necessários à avaliação e fornecendo feedback suficiente acerca do acompanhamento do mesmo (Lopes e Schiel, 2004).

Acerca do acompanhamento alternativo, os feitos dos discentes ao longo da sua trajetória acadêmica são judiciosamente avaliados conforme um rol de parâmetros subjetivos, viabilizando o feedback aos docentes no que se refere às qualidades e dificuldades apresentadas pelos mesmos. Adicionalmente, possibilita aos alunos a realização de reflexões e companhamentos acerca do próprio desempenho, bem como aferir a apreensão de "conhecimentos, habilidades e atitudes corroboradas pelos resultados do conjunto de trabalhos realizados” (Lopes e Schiel, 2004). 


\section{A relevância das disciplinas "afetas" à Contabilidade para o curso de Administração}

A contabilidade está inserida no contexto de sobrevivência das organizações por abastecer os gestores com "informações úteis e oportunas", viabilizando o atingimento da eficácia empresarial. Adicionalmente, a contabilidade preocupa-se em garantir o "melhor resultado econômico global”, uma vez que ela está relacionada à "gestão econômica de investimentos" da organização. A boa gestão é primordial àquela empresa que almeja alcançar resultados positivos e, por conseguinte, o lucro. Assim, a gestão eficiente e a contabilidade não podem ser dissociadas de forma alguma (Araujo, 2005). Para o autor a disciplina de contabilidade fornece aos alunos da graduação em administração os conceitos primários e secundários no manuseio das informações contábeis, subsidiando lhes a atuação acertada ao longo dos quatro níveis da tomada de decisão na organização: "estratégico, planejamento, execução e controle".

\section{Peculiaridades sobre o desempenho de homens e mulheres na Educação}

Lynn e Irwing (2004, 2005) realizaram pesquisa sobre a diferença de QI (quociente de inteligência) entre os sexos masculino e feminino e os resultados, contrariando a afirmação de vários pesquisadores como Eysenck (1981) e Anderson (2004), apontam que existe diferença de QI entre os sexos. Na pesquisa realizada em 2004, Lynn e Irwing concluíram que não há diferença no grau de inteligência de crianças de 6 a 15 anos de idade, mas a partir dos 16 anos a inteligência dos homens começa a se sobressair, chegando a uma diferença de 5 pontos de QI a partir dos 20 anos de idade. Na pesquisa, os autores realizaram uma meta-análise das diferenças de sexo em matrizes progressivas utilizando amostras da população em geral.

Quaisquerquesejam as causas destas diferenças, quando observado o desempenho educacional, as mulheres obtêm resultados cada vez melhores, chegando às vezes a superar os resultados masculinos. Há por exemplo, em termos de ensino superior no Reino Unido, em 1980, apenas $37 \%$ dos primeiros graus escolares foram obtidos por mulheres (Ramprakash e Daly, 1983, apud Lynn e Irwing, 2004), mas em 2001 este número subiu para 56\% (Matteson y Babb, 2002, apud Lynn e Irwing, 2004); nesse mesmo sentido, e Atém (1998), as mulheres, pela primeira vez, ultrapassaram os homens no desempenho escolar, conforme informações da Agência de Estatísticas de Educação Superior do Reino Unido. Esta vantagem feminina no desempenho educacional, quando comparada com os resultados da pesquisa sobre QI, sugere a existência de outros fatores que contribuem para essa conquista das mulheres e, 
segundo os autores, esse fato pode se dar por uma maior motivação das mulheres para o trabalho.

Posteriormente, Lynn e Irwing (2005) realizaram o mesmo trabalho, utilizando como amostra estudantes universitários, e confirmaram os resultados obtidos com amostras da população em geral. Os autores concluíram, ainda, que os homens têm maior capacidade de raciocínio que as mulheres e sugerem que este fato pode ser explicado pelo maior volume do cérebro masculino.

\section{Ciências Sociais Aplicadas e a Educação a Distância: outros estudos}

Outras pesquisas foram realizadas abordando o ensino de ciências sociais aplicadas utilizando-se a educação a distância.

Fandel et al. (1998) observaram o crescente número de estudantes, exames, programas de pós-graduação e ofertas de treinamento adicional em ciências econômicas. Reforçaram que a Universidade de Fern, na Alemanha, vem cumprindo o seu papel nesse processo, representando uma alternativa às Instituições de Ensino Superior existentes. Adicionalmente, contribui para a reforma do ensino no país e proporciona uma formação profissional complementar à coletividade. Convém reforçar que essa instituição têm se destacado na região da Renânia do NorteVestfália como um centro de excelência no ensino das ciências econômicas, na modalidade a distância.

Medina e Barroso (1999) conduziram uma pesquisa acerca das aplicações da Internet à educação à distância. A unidade de análise foi o sítio do Departamento de Economia Aplicada e História Econômica da Universidade Nacional de Educação a Distância (UNED), da Espanha. Os autores destacaram a visão empreendedora do Departamento, que soube aproveitar a tendência de popularização da Internet para incorporar essas novas tecnologias ao portal, fato que repercutiu especialmente nos hábitos dos usuários dos serviços disponibilizados por aquele órgão.

Sánchez et al. (2001) abordaram o modelo de ensino virtual da Universidade Nacional de Educação a Distância (UNED), situada na Espanha, tendo os autores delimitado o estudo à Faculdade de Ciências Econômicas da Instituição em lide. No estudo, os autores trataram dos instrumentos de treinamento baseados na internet e o papel que a rede mundial de computadores desempenha no aperfeiçoamento do ensino a distância. Relataram também os ensinamentos colhidos com a implantação de um curso introdutório de contabilidade e finanças na UNED, especialmente no 
que se refere às possibilidades de emprego dos recursos didáticos mais importantes da plataforma de treinamento em questão.

\section{METODOLOGIA}

\section{Tipo de Pesquisa}

Opresente estudoé uma pesquisa empírica exploratória, de abordagem qualitativa e quantitativa. É exploratória por consistir na coleta de dados e informações sobre um fenômeno pouco explorado em pesquisas, que pode ser explicado por meio do estudo de uma hipótese.

A pesquisa é também qualitativa por procurar descrever aspectos dos discentes como desempenho, sexo, idade e polo em que está matriculado, fatores que permitem definir o perfil do aluno do CEDERJ. Adicionalmente, o trabalho possui características de um estudo quantitativo por contabilizar os alunos do CEDERJ, em cada aspecto estudado, por meio de uma análise estatística dos dados.

\section{Coleta e Análise dos Dados}

O instrumento de pesquisa utilizado foi o banco de dados. As informações foram obtidas integralmente da base de dados do CEDERJ, disponibilizada para esta pesquisa. Para análise dos dados coletados utilizou-se o software "Statistical Package to Social Sciences for Windows" (SPSS).

Outra tecnologia levada à prática em método de avaliação on line é a "mineração de dados" ou data mining. Reside na extração de conformidades, modelos ou tendência de extenso volume de dados lançados em banco de dados com a intenção de conseguir conhecimentos proveitosos ao processo decisório. São gerados modelos de comportamento a partir dos dados colhidos, conforme a adaptação a critérios específicos. A técnica de mineração de dados não substitui por completo a tarefa do docente, porém beneficia o processo decisório no que se refere aos caminhos percorridos ao longo do processo de ensino-aprendizagem (Marçula e Benini Filho, 2009).

Carpenter e Lachtermacher (2005) realizaram estudo aplicando a metodologia de mineração de dados (data mining) com a finalidade de descobrir o conhecimento implícito em um banco de dados de alunos do sistema acadêmico de uma instituição de ensino superior (IES). Para isso analisou-se alguns dados destes alunos, 
associando-os com o desempenho obtido por eles para determinar os fatores que mais afetam o desempenho dos alunos. Para cumprir este objetivo foi utilizado um software específico para mineração de dados (data mining), sendo possível, ao final, obter uma série de novos conhecimentos.

Freitas et al. (2007) realizaram pesquisa sobre conceitos, técnicas e aplicações desta metodologia e concluíram que esta técnica tende a englobar novas áreas de atuação em virtude de seu potencial em revelar conhecimentos não triviais ao pensamento humano. Para os autores este potencial crescimento tem despertado empresas e grupos de pesquisa para a necessidade de aprimorar as técnicas existentes e desenvolver novas técnicas, respaldando especialistas das mais diversas áreas a atuarem na descoberta do conhecimento implícito.

As hipóteses nulas testadas neste estudo são as seguintes:

(i) Ha: Não existe diferença entre o desempenho dos discentes nas disciplinas de contabilidade, quando comparados os sexos dos alunos do CEDERJ; e,

(ii) Hb: Não existe diferença entre o desempenho dos discentes nas disciplinas de contabilidade, quando comparados os polos nos quais os alunos do CEDERJ estão matriculados.

\section{ANÁLISE E DISCUSSÃo}

Nessa fase, é proposta uma "abordagem semi-automática para extração de conhecimento", amparado em estratégias de mineração de dados, objetivando gerar "regras, padrões, tendências e/ou associações" afetos às características dos discentes guardadas no banco de dados. Esses padrões são capazes de expor um conhecimento de grande utilidade no que tange à condução do aprendizado (Lopes e Schiel, 2004).

Para iniciar a análise comparativa dos desempenhos dos discentes do CEDERJ foi necessário levantar a estimativa de alunos matriculados no curso bem como o percentual de homens e mulheres em cada período letivo. 


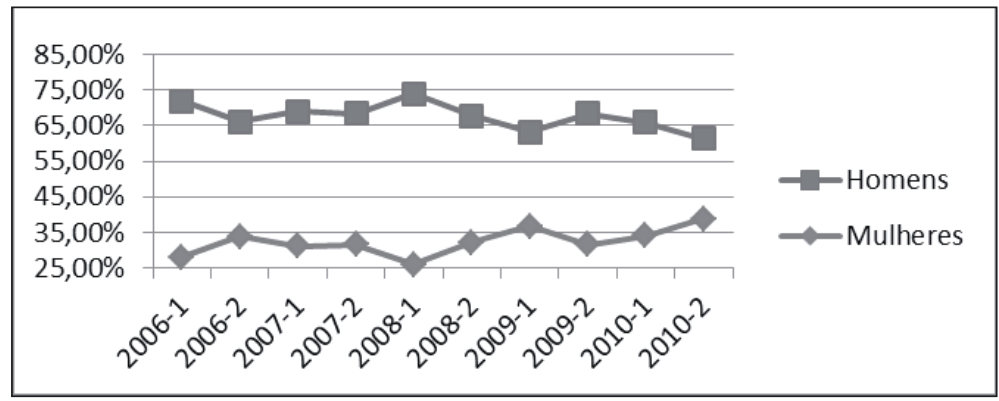

Gráfico 1. Variação percentual entre alunos homens e mulheres matriculados

Pelo gráfico 1 é possível identificar que os homens representavam, aproximadamente, $75 \%$ dos alunos matriculados no primeiro semestre de 2006. Os demais períodos letivos foram caracterizados por uma relativa redução no percentual de homens matriculados e, no segundo semestre de 2010, os homens totalizavam menos de $65 \%$ dos alunos matriculados.

Notadamente, a redução em cerca de 10\% em relação ao número de mulheres, no período de 2006 a 2010, demonstra uma tendência de redução no número de homens matriculados no CEDERJ. Tal fato pode estar associado diretamente à questão da capacitação profissional. A mulher vem conquistando nos últimos anos o seu espaço no mercado de trabalho e como reflexo natural dessa tendência o mercado tem exigido uma maior capacitação das mulheres que vêem na educação a distância uma oportunidade de preencher essa lacuna, mitigando a variação percentual entre os gêneros dos discentes.

Para compor o perfil dos discentes, registrou-se a idade dos alunos do CEDERJ em cada sexo, permitindo identificar a faixa etária de cada grupo. 


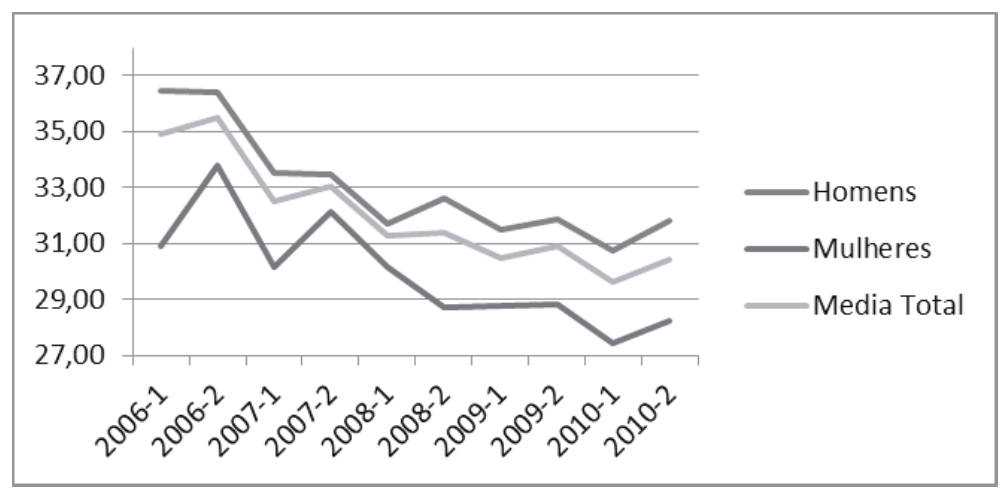

Gráfico 2. Média de idade de alunos por sexo

O gráfico 2 descreve que a média de idade dos homens matriculados no CEDERJ variou de 36 anos, no início de 2006, para 32 anos, ao final de 2010. Acompanhando essa tendência, a média das mulheres reduziu de 31 para 28 anos, demonstrando uma significativa redução na média das idades dos alunos matriculados. É razoável inferir que um percentual maior de alunos procedentes do ensino médio, com menor idade, tem optado pelo Ensino à Distância.

Para comprovar o resultado foi efetuada a contagem dos discentes do CEDERJ por faixa etária para demonstrar graficamente a tendência das idades dos alunos ao longo do tempo, conforme gráfico 3.

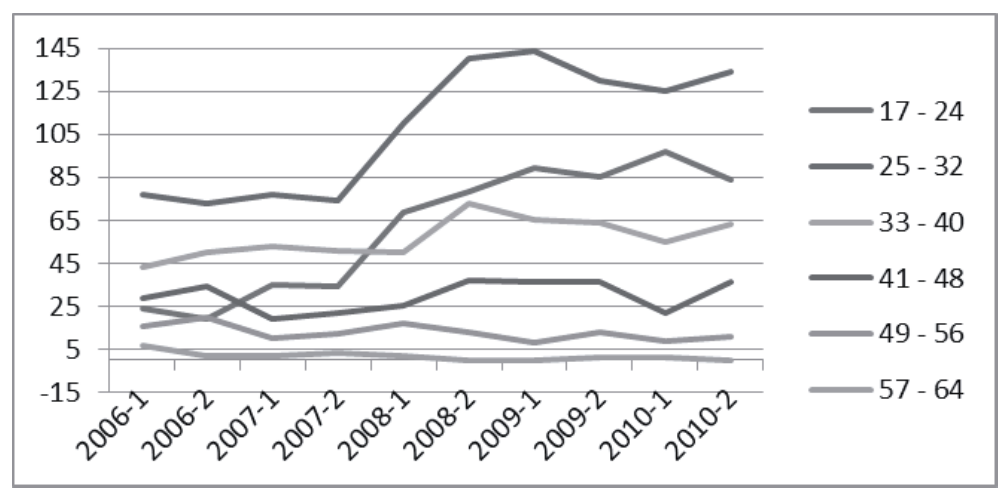

Gráfico 3. Distribuição de faixa etária dos alunos

Corroborando com a observação do gráfico anterior, o gráfico 3 demonstra um significativo aumento no número de alunos, nas faixas etárias de 17 a 24 anos e 25 
a 32 anos. No início de 2006, apenas 25 alunos, na faixa de 17 a 24 anos, estavam matriculados no CEDERJ, enquanto, ao final de 2010, esse quantitativo aumentou para 85 alunos. De forma bem similar, na faixa etária de 25 a 32 anos, o número de matriculados aumentou de 75, em 2006, para 135, em 2010.

Percentualmente, as faixas etárias de 17 a 24 anos e 25 a 32 anos, representavam pouco mais de 50 \% dos alunos matriculados, no início de 2006. Por outro lado, no segundo semestre de 2010, esse percentual aumentou para 65\% dos alunos, o que justifica a redução na média das idades dos discentes.

Adicionalmente, pode-se perceber que a quantidade média de alunos matriculados nas faixas etárias de 41 a 64 anos se manteve praticamente constante durante o período estudado. A ilustração abaixo apresenta a distribuição das faixas etárias em cada sexo.

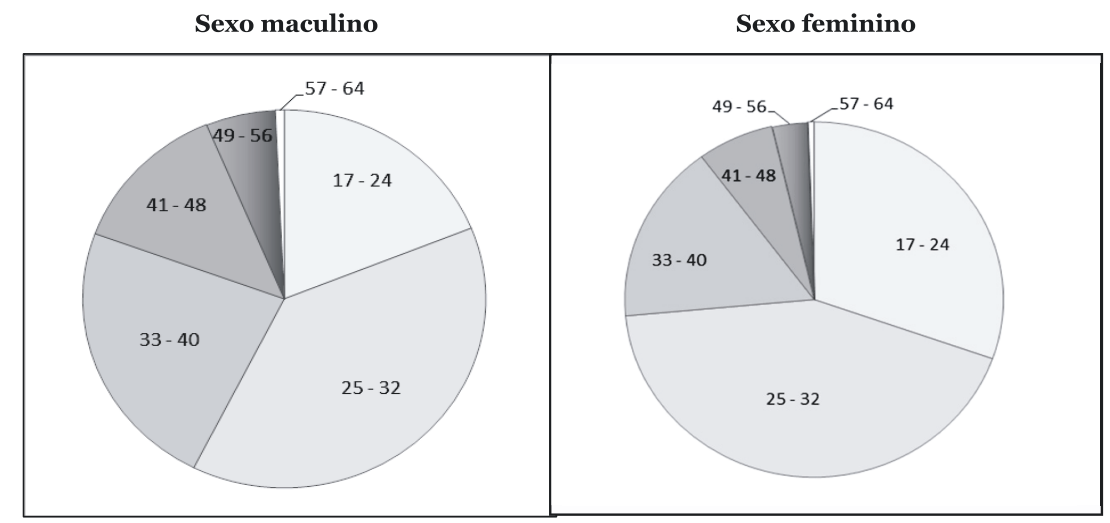

Gráfico 4. Distribuição de faixa etária dos alunos

Os resultados apontam que, proporcionalmente, a faixa etária das mulheres de 41 a 64 anos é muito inferior a dos homens, sugerindo que as mulheres ao atingirem 41 anos têm menor propensão de estarem cursando ensino a distância no CEDERJ.

No gráfico abaixo buscou-se relacionar as médias obtidas por homens e mulheres nos últimos vestibulares do CEDERJ, para avaliar o desempenho obtido por ocasião do ingresso. 


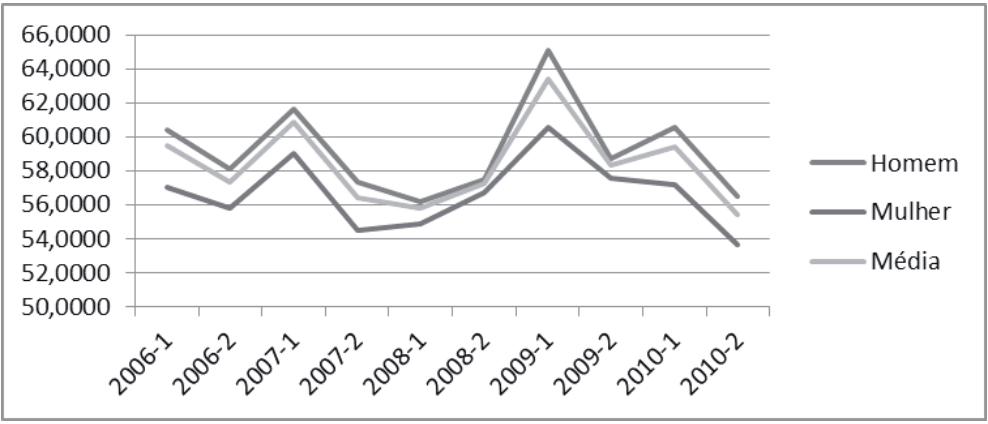

Gráfico 5. Nota de ingresso pelo vestibular

Pode-se observar que, historicamente, os homens têm apresentado melhores médias de notas no vestibular e, ao considerar que os vestibulandos são jovens e adultos com idade superior a 17 anos, estes resultados podem ser explicados pelas observações de Lynn e Irwing (2004). Para aqueles autores, a partir dos 16 anos o QI dos homens é maior do que o das mulheres, chegando a uma diferença de 5 pontos a partir dos 20 anos.

Entretanto, apesar destas diferenças de QI, Lynn e Irwing (2004) identificaram que, em termos de desempenho educacional, as mulheres têm obtido resultados cada vez melhores, chegando, às vezes, a superar os resultados masculinos.

Para testar a hipótese proposta na metodologia, foram quantificados por sexo as médias históricas em cada disciplina de Contabilidade do curso de Administração do CEDERJ.

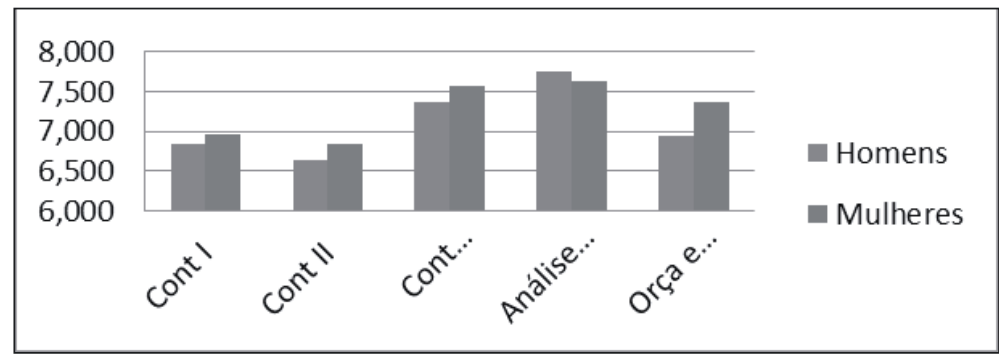

Gráfico 6. Média das disciplinas afetas à Contabilidade por sexo. 
Quando comparados os desempenhos dos discentes, pode-se observar que nas disciplinas orçamento e custo de capital, contabilidade I, contabilidade II e contabilidade gerencial as mulheres apresentaram médias superiores às dos homens. Os resultados corroboram com as observações de Lynn e Irwing (2004), constatandose que as mulheres apresentam um desempenho educacional melhor que os homens, o que permite rejeitar a hipótese nula (Ha), e afirmar que o desempenho dos discentes é diferente quando comparados os sexos dos alunos do CEDERJ.

Esta vantagem feminina no desempenho educacional, quando comparada com o maior QI dos homens, observado por Lynn e Irwing (2004), sugere que existem outros fatores que contribuem para esse resultado obtido pelas mulheres. Os autores apontam que esse fato pode se dar por uma maior motivação das mulheres para 0 trabalho.

Pesquisa de Vargas e Lima (2004) apontou que as mulheres são mais persistentes que os homens e esse achado é coerente com a observação acerca das questões afetas a gênero e aprendizagem on-line, conduzida por McSporran, Macleod e French (2003, apud Vargas e Lima, 2004), cujo trabalho indicou que as mulheres possuem um desempenho superior ao dos homens.

Neste segundo momento, procurou-se analisar o desempenho dos discentes matriculados em polos distintos. A fim de auxiliar a análise, a tabela 2 apresenta as distâncias de cada polo em relação ao município do Rio de Janeiro. Esta informação, agregada ao desempenho dos discentes em cada pólo, contribui para uma melhor reflexão sobre os resultados da metodologia de ensino à distância, bem como para os ajustes necessários na estratégia adotada.

\begin{tabular}{|l|l|l|l|l|l|l|l|l|l|}
\hline \multicolumn{2}{|c|}{ Distância dos municípios em relação ao município do Rio de Janeiro } \\
\hline & $\begin{array}{l}\text { Angra dos } \\
\text { Reis } \\
\text { (ARE) }\end{array}$ & $\begin{array}{l}\text { Itaperuna } \\
\text { (ITA) }\end{array}$ & $\begin{array}{l}\text { Magé } \\
\text { (MAG) }\end{array}$ & $\begin{array}{l}\text { Piraí } \\
\text { (PIR) }\end{array}$ & $\begin{array}{l}\text { Saquarema } \\
\text { (SAQ) }\end{array}$ & $\begin{array}{l}\text { São } \\
\text { Fidélis } \\
\text { (SFI) }\end{array}$ & $\begin{array}{l}\text { São } \\
\text { Gonçalo } \\
\text { (SGO) }\end{array}$ & $\begin{array}{l}\text { Resende } \\
\text { (RCE) }\end{array}$ & $\begin{array}{l}\text { Rio das } \\
\text { Flores } \\
\text { (RFL) }\end{array}$ \\
\hline Km & 151 & 365 & 70 & 103 & 102 & 285 & 30 & 161 & 181 \\
\hline
\end{tabular}

Tabela 2. Distância dos Pólos do CEDERJ em relação ao centro do município do Rio de Janeiro Fonte: Adaptado de Guia Log - Distâncias em Km com origem no Rio de Janeiro

O gráfico seguinte apresenta, para cada polo, a série histórica com as médias das notas dos discentes por ocasião do vestibular. 


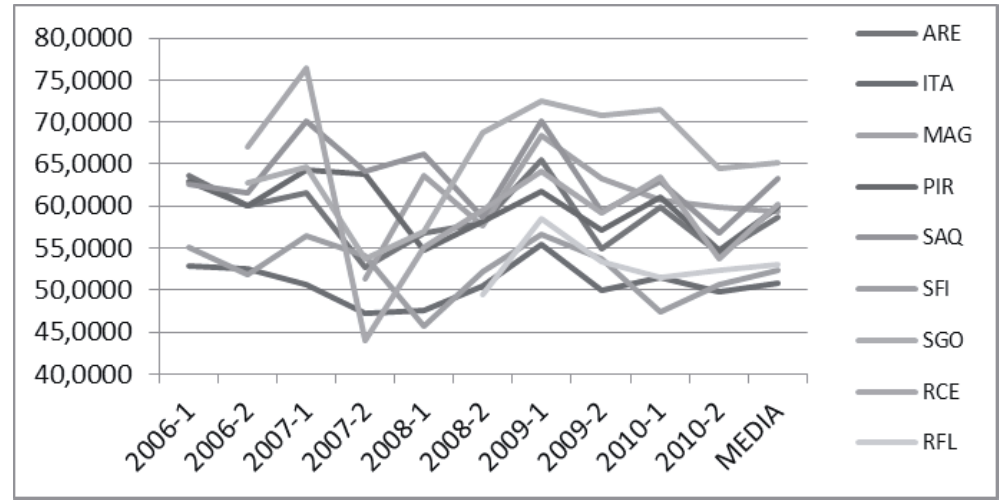

Gráfico 7. Notas dos discentes no vestibular em cada polo

Os resultados dos vestibulares em cada polo apontam que, na média, os melhores desempenhos no vestibular são alcançados nos polos de São Gonçalo (média 65,11), Saquerema (média 63,26) e Rezende (média 60,28), enquanto os piores resultados foram observados nos polos de São Fidelis (média 52,39), Rio das Flores (média 53,08) e Itaperuna (média 50,80).

Por outro lado, para mensurar o desempenho dos discentes durante o curso, foi calculada a média dos discentes em cada polo.

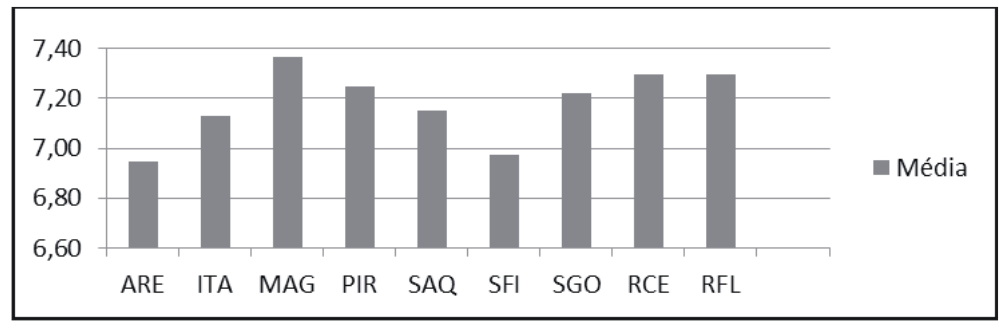

Gráfico 8. Média dos alunos por polo durante o curso

Os resultados indicam que a maiores médias foram obtidas nos polos de Magé (média 7,36), Rio das Flores (média 7,29) e Rezende (média 7,29), enquanto as piores médias foram observadas nos polos de São Fidelis (média 6,98) e Angra dos Reis (média 6,95). Os achados desta pesquisa apontam para a existência de diversas médias diferentes em cada polo o que permite rejeitar a hipótese nula ( $\mathrm{Hb})$ 
e afirmar que existe diferença entre o desempenho dos discentes nas disciplinas de contabilidade, quando comparados os polos nos quais os alunos do CEDERJ estão matriculados.

Vale ressaltar que o polo de Rio das Flores apresentou uma das menores médias do vestibular, mas quando verificadas as notas durante o curso dos alunos deste polo, pode-se constatar aqueles discentes tiveram um dos melhores desempenhos.

Pardini et al. (2008) realizaram pesquisa sobre a influência dos atributos comportamentais e demográficos no relacionamento e desempenho dos alunos de graduação em um curso de administração da cidade de Belo Horizonte. Os autores constataram que, para a maior parte dos entrevistados, a localização residencial pode afetar negativamente o desempenho dos alunos, em virtude do cansaço decorrente dos trajetos diários entre residência e escola. Por outro lado, a naturalidade e a idade dos alunos não afetam o desempenho.

O gráfico que se segue apresenta os percentuais de aprovação dos discentes pelos respectivos sexos.

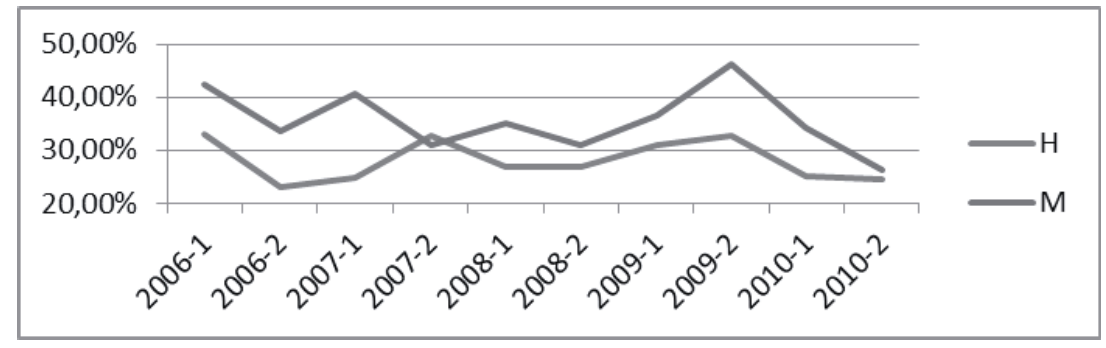

Gráfico 9. Percentual de aprovações dos alunos por sexo

No gráfico 9, observa-se que as mulheres historicamente apresentam um percentual de aprovação superior ao dos homens, exceto no segundo semestre de 2007, quando o percentual de aprovação dos alunos do sexo masculino foi de $32,66 \%$, ao passo que o feminino foi de 31 , o8\%. Para um melhor entendimento, a tabela abaixo descreve os resultados em números.

\begin{tabular}{|c|r|c|c|c|c|c|c|c|c|c|}
\hline GÊNERO & $2006-1$ & $2006-2$ & $2007-1$ & $2007-2$ & $2008-1$ & $2008-2$ & $2009-1$ & $2009-2$ & $2010-1$ & $2010-2$ \\
\hline H & $32,97 \%$ & $23,00 \%$ & $24,82 \%$ & $32,66 \%$ & $26,88 \%$ & $26,97 \%$ & $30,85 \%$ & $32,86 \%$ & $25,00 \%$ & $24,62 \%$ \\
\hline M & $42,26 \%$ & $33,52 \%$ & $40,60 \%$ & $31,08 \%$ & $34,98 \%$ & $30,88 \%$ & $36,61 \%$ & $46,22 \%$ & $34,26 \%$ & $26,19 \%$ \\
\hline
\end{tabular}

Tabela 3. Percentual de aprovação dos alunos 
O gráfico 9 e a tabela apresentam o índice de aprovação entre homens e mulheres e os resultados convergem com a observação sobre o desempenho dos discentes. Ou seja, as mulheres alcançaram um melhor desempenho durante o curso e apresentaram um maior percentual de aprovação.

O gráfico abaixo relata o desempenho dos discentes em cada disciplina afeta à Contabilidade.

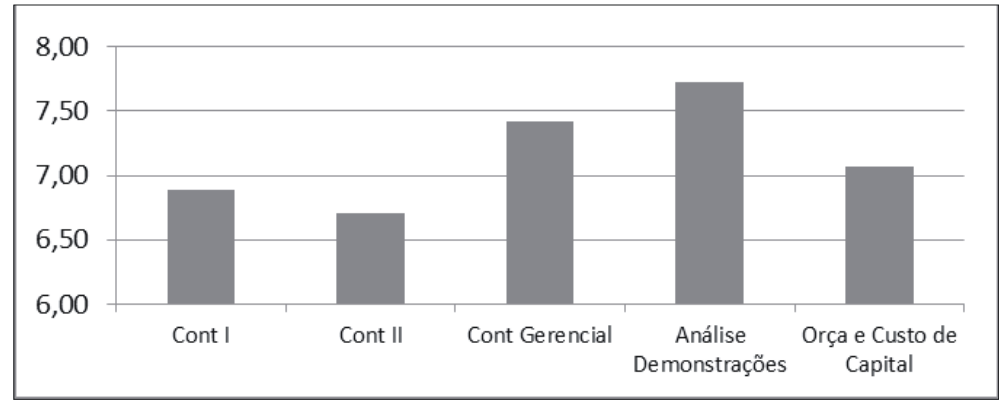

Gráfico 10. Médias dos alunos nas disciplinas afetas à Contabilidade

Os resultados indicam que as maiores médias são obtidas nas disciplinas de Análise das Demonstrações (média 7,72) e Contabilidade Gerencial (média 7,41). Por conseguinte, as menores médias foram observadas nas disciplinas de Contabilidade II (média 6,71), Contabilidade I (média 6,88) e Orçamento e Custo de Capital (média 7,07). Para auxiliar na análise dos dados, as médias foram calculadas para cada período do curso, conforme gráfico 11.

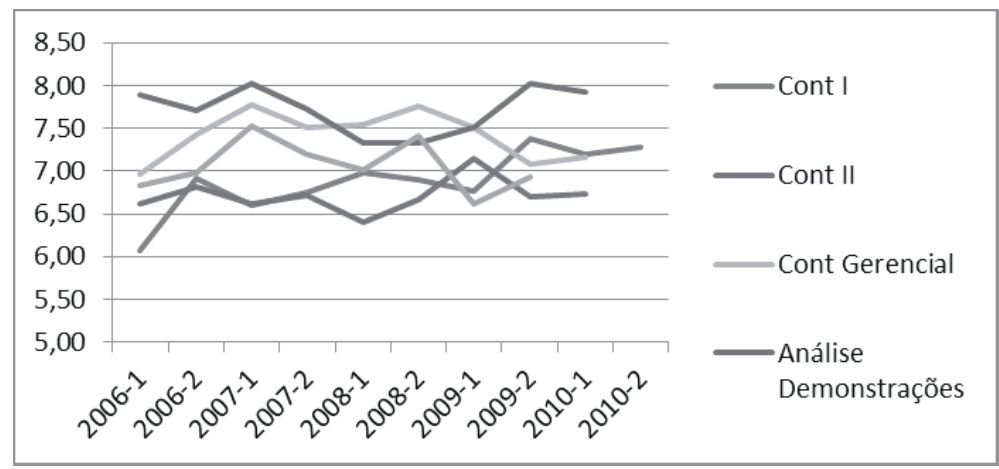

Gráfico 11. Médias dos alunos nas disciplinas afetas à Contabilidade por período 
As informações constantes no gráfico 11 corroboram o que foi exposto no gráfico 10. É apresentada a média geral de cada uma das disciplinas avaliadas no período em questão, constatando-se que o desempenho dos alunos foi melhor nas disciplinas de análise das demonstrações contábeis e contabilidade gerencial.

\section{CONSIDERAÇÕES FINAIS}

Os resultados encontrados na pesquisa, em grande parte, são corroborados pelos textos já publicados. Entretanto, importa mencionar que alguns achados são muito relevantes e contribuem para ampliar o conhecimento sobre o tema.

Pela pesquisa foi possível identificar que as mulheres têm um aproveitamento superior ao dos homens, tendo em vista que entram com média inferior no vestibular, mas durante o curso alcançam os melhores resultados. Importa mencionar que, Lynn e Irwing (2004), comprovaram que os homens, a partir dos 16 anos, têm maior QI que as mulheres, mas, quando comparado o desempenho dos discentes durante o curso, as mulheres obtêm os melhores resultados.

Este resultado permitiu rejeitar a hipótese rejeitar a hipótese (Ha), e afirmar que os desempenhos dos discentes são diferentes quando comparados os sexos dos alunos do CEDERJ. Há por exemplo,o gráfico 9 e a tabela 3 apresentam o índice de aprovação entre homens e mulheres e os resultados convergem com a observação sobre o desempenho dos discentes. Ou seja, as mulheres alcançaram um melhor desempenho durante o curso e apresentaram um maior percentual de aprovação.

Os desempenhos nos vestibulares apontam que os melhores resultados foram alcançados nos polos de São Gonçalo, Saquerema e Magé, enquanto os piores foram observados nos polos de São Fidelis, Rio das Flores e Itaperuna.

Entretanto, ao medir o desempenho dos discentes durante o curso observou-se que as maiores médias foram obtidas nos pólos de Magé, Rio das Flores e Rezende, enquanto as piores médias foram observadas nos pólos de São Fidelis e Angra dos Reis. Estes achados permitiram rejeitar a hipótese nula ( $\mathrm{Hb})$ e afirmar que existe diferença entre o desempenho dos discentes nas disciplinas de contabilidade, quando comparados os polos nos quais os alunos do CEDERJ estão matriculados.

Notadamente, como qualquer outra pesquisa, este estudo apresenta limitações que devem ser consideradas pelos leitores. O objetivo deste estudo é traçar o perfil de discentes do curso de ensino a distância em administração do CEDERJ, matriculados 
nas disciplinas de contabilidade. Assim, os achados estão limitados aos aspectos das disciplinas estudadas no curso do CEDERJ e a generalização dos resultados por parte dos leitores, requer cuidado em função destas limitações.

\section{REFERÊNCIAS BIBLIOGRÁFICAS}

Abdala, E. A.; Testa, M. G.; Gusmão, S. L. L. (2007). Disciplinas a Distância em Cursos de Graduação em Administração: Um Estudo de Caso na PUCRS. EnEPQ.

Almeida, J. S. G. (2001). A avaliação da aprendizagem escolar e a função social da escola. Dissertação de Mestrado. Pontifícia Universidade Católica de São Paulo, São Paulo.

Anderson, M. (2004). Sex differences in general intelligence. In: Gregory, R. L. (Ed.). The Oxford companion to the mind. Oxford, UK: Oxford University Press.

Araujo, A. F. de (2005). Qual o Papel da Disciplina de Contabilidade no Curso de Administração. Revista Eletrônica de Administração, Garça, 8, (1-26).

Bahia, N. P.; Duran, M. C. G. (2011). Carrera de Pedagogía a Distancia: obstáculos en la proposición de la carrera como formación inicial. RIED. Revista Iberoamericana de Educación a Distancia, 14 (2). [en línea] Disponible en: http://www.utpl. edu.ec/ried/images/pdfs/volum14-2/ carreradepedagogia.pdf (consulta 2012, 21 de junio).

Brasil. Ministério da Educação. (2012). Educação a distância. [em líea] Disponível em: http://portal.mec. gov.br/index.php?option $=$ com jf ilter\&Itemid =164\&params[sea rch relevance]=EDUCAÇÃO A DISTANCIA\&params[search meth od]=exact\&params[tipobusca] $=$ null (consulta 2012, 21 de junio).

Caldeira, A. C. M. (2004). Avaliação da Aprendizagem em meios digitais: novos contextos. XI Congresso Internacional de Educação a Distância, Salvador. Anais do XI Congresso de Educação a Distância.

Carpenter, E. O.; Lachtermacher, G. (2005). Determinação dos Fatores Críticos na Análise de Desempenho do Corpo Discente de Cursos de Pós-graduação Lato Sensu Utilizando Metodologia Data Mining. ENANPAD.

Eysenck, H. J. (1981). In: Eysenck, H. J.; Kamin, L. (Eds.). Intelligence: The battle for the mind: H. J. Eysenck versus Leon Kamin. London: Pan. (1189).

Fandel, G.; Hoffmann, H.; Streubel, W. (1998). Éxitos Perspectivas y Aspectos Críticos de la Educación a Distancia en Ciencias Económicas en la FernUniversität Hagen. RIED. Revista Iberoamericana de Educación a Distancia, 1 (1). [em línea] Disponible en: http://www. utpl.edu.ec/ried/images/pdfs/vol1-1/ art5exitosperspectivasaspectos.pdf (consulta 2012, 21 de junio).

Freitas, C.; Nascimento, D.; Couto, M.; Santana, L. (2007). Data Mining: Conceitos, Técnicas e Aplicações. Universidade Federal da Bahia. [em línea] Disponível em: http://twiki2. dcc.ufba.br/pub/MATA6o/WebHome/ DataMining.pdf (consulta 2011, 20 de noviembre).

David, P. B.; Silva, A. S. R.; Souza, C. F.; Viana-Júnior, G. S.; Castro-Filho, J. A.; Pequeno, M. C.; Ventura, P. P. B.; Maia, S. M. (2007). Avaliação da Aprendizagem em Educação a Distância numa Perspectiva Sócio-Interacionista. 
XVIII Simpósio Brasileiro de Informática na Educação, São Paulo. Anais do XVIII Simpósio Brasileiro de Informática na Educação.

Haydt, R. C. (2002). Avaliação do processo ensino-aprendizagem. São Paulo: Ática.

Libâneo, J. C. (1991). Didática. São Paulo, Cortez.

Linderman, R. H. (1986). Medidas Educacionais. $1^{\text {a }}$ Edição. Rio

Grande do Sul: Editora Globo.

Lopes, C. C.; Schiel, U. (2004). Uma Estratégia para Aplicar Mineração de Dados no Acompanhamento do Aprendizado na EaD. XIII Seminco, Blumenau. Anais do XIII Seminco.

Lynn, R.; Irwing, P. (2005). Sex differences in means and variability on the progressive matrices in university students: A meta-analysis. British Journal of Psychology, 96, (505-524).

Lynn, R.; Irwing, P. (2004). Sex differences on the progressive matrices: A metaanalysis. Intelligence, 32, (481-498).

Luckesi, C. (1998). Verificação ou avaliação: o que pratica a escola? Avaliação da Aprendizagem Escolar: Estudos $e$ Proposições. São Paulo: Cortez, (85101).

Marçula, M.; Benini Filho, P. A. (2009). Informática - Conceitos e Aplicações. 3. ed. São Paulo: Editora Érica.

Medina, J. C.; Barroso, J. L. G. (1999). Aplicaciones de Internet en la enseñanza a Distancia: la página Web del Departamento de Economía aplicada e historia económica de la UNED. RIED. Revista Iberoamericana de Educación a Distancia, 2 (1). [en línea] Disponible en: http://www. utpl.edu.ec/ried/images/pdfs/vol2-1/ aplicacioens internet.pdf (consulta 2012, 21 de junio).

Mora, L. F. M.; Gómez, M. J. R. (2011). Determinantes inmediatos del rendimiento académico en los nuevos estudiantes matriculados en el sistema de educación superior a distancia del Ecuador: caso Universidad Técnica Particular de Loja. RIED. Revista Iberoamericana de Educación a Distancia, 14 (2). [en línea] Disponible en: http://www.utpl.edu. ec/ried/images/pdfs/volum14-2/ determinantesrendimientoacademico. pdf (consulta 2012, 21 de junio).

Mota, R. (2007). Universidade Aberta do Brasil. ABRAEAD. [em línea] Disponível em: http://www.abraead. com.br/artigos ronaldo.html (consulta 2011, 25 de octubre).

Pacheco, A. S. V. et al. (2008). Evasão: Análise da Realidade do Curso de Graduação em Administração a Distância da Universidade Federal de Santa Catarina. EnANPAD.

Pardini, D. J.; Falcão, B. M.; Santos, R. V. (2008). Diversidade no Meio Universitário: Influência dos Atributos Comportamentais e Demográficos no Relacionamento e Desempenho de Alunos de Graduação em Administração. ENANPAD.

Perrenoud, P. (1999). Avaliação: da excelência à regulação das aprendizagens: entre duas lógicas. Porto Alegre: ArtMed.

Piletti, C. (1987). Didática geral. São Paulo: Ática.

Prata, D. N. (2003). Estratégias para o Desenvolvimento de um Framework de Avaliação da Aprendizagem a Distancia. XIV Simpósio Brasileiro de Informática na Educação, Inclusão Digital como Instrumento de Inclusão Social. Rio de Janeiro: Nucleo de Computação Eletrônica. (150-159).

Sánchez, D. D. L. F.; Merchante, A. M.; Pedreira, M. S. (2001). El modelo de enseñanza virtual en la UNED. Desarrollo de un curso en la Facultad de Económicas. RIED. Revista Iberoamericana de Educación a 
Distancia, 4(1). [en línea] Disponible en: http://www.utpl.edu.ec/ried/images/ pdfs/vol4-1/modelo ensenanza.pdf (consulta 2012, 21 de junio).

Santos, J. F. S. (2006). Avaliação no ensino a distância. Revista Iberoamericana de Educación (Online), 38 (4), Madrid.

Secca, R. X.; Leal, R. M. (2009). Análise do setor de ensino superior privado no Brasil. BNDES Setorial, 30, (1).
Schlickmann, R.; et al. (2009). Fatores Determinantes na Opção do Aluno pela Modalidade a Distância: Um Estudo nos Cursos de Graduação em Administração das Universidades Catarinenses. EnADI.

Vargas, M. R. M.; Lima, S. M. V. (2004). Barreiras à Implantação de Programas de Educação e Treinamento a Distância. $X I$ Congresso Internacional de Educação a Distância, Salvador-BA.

\section{PERFIL ACADÊMICO E PROFISSIONAL DOS AUTORES}

Robson Augusto Dainez Condé. Graduado em Ciências Navais (Escola Naval) e em Direito e Mestrando em Contabilidade pela Universidade do Estado do Rio de Janeiro (UERJ). Atua profissionalmente como Auditor-Fiscal da Receita do Estado do Espírito Santo. Suas áreas de interesse são: Ensino e Pesquisa em Administração e Contabilidade, Administração Pública, Auditoria, Contabilidade e Indústria de Defesa.

E-mail: robsonconde.mcc.uerj@hotmail.com

Renato Santiago Quintal. Bacharel em Ciências Navais (Escola Naval) e em Administração de Empresas (Universidade Cândido Mendes) e Especialista em Comércio Exterior pela Universidade Federal do Rio de Janeiro. Atualmente, cursa o Mestrado em Contabilidade pela Universidade do Estado do Rio de Janeiro (UERJ). No âmbito profissional, é Oficial da Ativa do Corpo de Intendentes da Marinha do Brasil. Suas áreas de interesse são: Ensino e Pesquisa em Administração e Contabilidade, Administração Pública, Auditoria, Contabilidade e Indústria de Defesa.

E-mail: rsantiago79@hotmail.com

Silvestre de Mello de Souza. Bacharel em Administração de Empresas pela Universidade Estácio de Sá e Mestrando em Contabilidade pela Universidade do Estado do Rio de Janeiro (UERJ). Atua profissionalmente como Professor da Fundação de Apoio à Escola Técnica na Cidade do Rio de Janeiro. Suas áreas de interesse são: Ensino e Pesquisa, Administração Pública, Auditoria e Contabilidade.

E-mail: admin@professorsilvestre.com 
SimoneSilva da Cunha Vieira. Bacharel em Ciências Contábeis (Universidade do Estado do Rio de Janeiro), Mestre em Ciências Contábeis (Universidade do Estado do Rio de Janeiro) e Doutora em Contabilidade e Controladoria (Universidade de São Paulo). É professora do Programa de Mestrado em Ciências Contábeis da Universidade do Estado do Rio de Janeiro. Suas áreas de interesse são: Ensino e Pesquisa, Administração Pública, Auditoria e Contabilidade.

E-mail: simoneantonio@uol.com.br

DIRECCIÓN DE LOS AUTORES

Universidade do Estado do Rio de Janeiro (UERJ) - Programa de Mestrado em Ciências Contábeis

Rua São Francisco Xavier, 524, $9^{\circ}$ andar, Bloco E, Maracanã, Rio de Janeiro-RJ, CEP: 20550-013 Rio de Janeiro-RJ Brasil.

Fecha de recepción del artículo: 12/01/2012

Fecha de aceptación del artículo: 27/06/2012

\section{Como citar este artículo:}

Dainez Condé, R. A.; Quintal, R. S.; De Mello De Souza, S.; Silva Da Cunha Vieira, S. (2013). O perfil dos alunos de administração matriculados nas disciplinas da área contábil: o caso do Centro de Educação a Distância do Estado do Rio de Janeiro (CEDERJ). RIED. Revista Iberoamericana de Educación a Distancia, volumen 16, $\mathrm{n}^{0} 1$, pp. 173-198. 